\title{
(Proto)escritores de ciencia en Cienciorama
}

\author{
Adriana Pliego, Carlos Alberto Velázquez Olivera, Edgar Var- \\ gas Frías, Mariana Esther Martínez-Sánchez y Silvia Zenteno
}

\section{Resumen}

Vivimos rodeados por la ciencia, desde el humilde asfalto que pisamos hasta la supercomputadora en nuestros bolsillos; el mundo a nuestro alrededor es el resultado de los avances en la ciencia y la tecnología; por ello es fundamental que las personas puedan acceder al conocimiento científico y tecnológico. De esta necesidad surge la importancia de la divulgación científica, ya que les da a las personas las herramientas para entender y cuestionar el mundo que los rodea. En ese entendimiento, los científicos tenemos un papel crucial porque muchos de nosotros hemos dedicado años de estudio —con recursos públicos en la mayoría de los casos - a la ciencia y la tecnología que soporta nuestra civilización. Sin embargo, traducir esos años de estudio en conceptos asequibles para otras personas no es trivial. Afortunadamente, la comunicación es una habilidad que puede ser aprendida y de ahí nace la importancia de talleres y portales de divulgación de la ciencia como Cienciorama. A continuación presentamos los testimonios y experiencias de cinco de los estudiantes que colaboran en el taller y cómo ha impactado, no sólo su visión de la ciencia, sino de la política, el arte y la vida.

Palabras clave: taller, portal, internet, divulgación, conocimiento, ciencia, lenguaje, creatividad, cultura, libertad, democracia.

\section{(Proto)science writers in Cienciorama}

\begin{abstract}
We live surrounded by science, from the humble asphalt where we walk to the supercomputer in our pockets, the world that surrounds us is the result of advances in science and technology. This is why access to scientific knowledge is fundamental for people. From this necessity arises the importance of science outreach, as it gives people the tools to understand and question the world around them. In this process, we scientists have a crucial role, since many of us have devoted years of study — with public resources in most cases - to the science and technology that our civilization supports. However, translating those years of study into concepts that are accessible to other people is not trivial. Fortunately, communication is a skill that can be learned, from which the importance of workshops and portals for science outreach as Cienciorama is born. Below we present the testimonies of five of the students who collaborate in the workshop, who explain their experience in the workshop and how it has impacted not only their vision of science but also of politics, art, and life.
\end{abstract}

Key words: workshop, portal, internet, popularization, knowledge, science, language, creativity, culture, freedom, democracy. 


\section{Adriana Pliego}

Ingeniera Biomédica por la Universidad Autónoma Metropolitana. Maestra en Ciencias Fisiológicas por la Benemérita Universidad Autónoma de Puebla donde actualmente realiza sus estudios de Doctorado. Profesora de Tiempo Completo en la Universidad Autónoma del Estado de México en la Licenciatura de Bioingeniería Médica. Trabaja en investigación relacionada con la sustitución de la función vestibular y el estudio de la postura erguida mediante el desarrollo y evaluación de dispositivos biomédicos. Tiene interés en desarrollarse en el área de medicina espacial, abordando el restablecimiento del reflejo vestíbulo-ocular en astronautas. Es autora de artículos de divulgación científica publicados en revistas como Elementos de la BUAP y Deveras de COMECyT. Colabora en el Taller/Portal Cienciorama desde 2013.

\section{Carlos Alberto Velázquez Olivera}

Doctor en Física, egresado del Instituto de física de la UNAM en 2017. Sus líneas de investigación se han extendido desde el área de la óptica, estudiando la polarización de la luz y para comprender su interacción con superficies estructuradas, hasta la física de fluidos investigando solitones en el torrente sanguíneo y en el área de cristales líquidos. Ha publicado dos artículos de investigación, uno acerca del estudio de un polarímetro para el estudio de superficies estructuradas, y otro acerca del fenómeno de radiación Cherenkov y radiación de Transición en cristales líquidos colestéricos, con vista a su aplicación como nueva herramienta de detección de radiación. Ha participado en varias actividades de divulgación de la ciencia y Colabora en el Taller/Portal Cienciorama desde 2014.

\section{Edgar Vargas Frías}

Licenciado en Química y Maestro en Ciencias Químicas. Actualmente es candidato a doctor en Ciencias Químicas. Todos los grados los obtuvo en la UNAM. Ganador del "Premio Nacional Cinvestav 2013" a la mejor tesis de maestría en el área de ciencia exactas y naturales. Ha sido representante de alumnos ante el comité académico del mismo posgrado en el periodo 2013-2015. Es miembro fundador de la sociedad estudiantil de divulgación científica "Bohrium, comunidad de ciencias del espacio". Cuenta con experiencia en divulgación de la ciencia en medios electrónicos (texto y video); ha sido conferenciante, expositor y tallerista en eventos y ferias científicas. Colaborador del Taller/ Portal Cienciorama desde 2014 y Administrador del Portal y manejo de redes desde 2018.

Miembro de la Asamblea Nacional de Estudiantes de Posgrado (ANEP), del comité organizador de la "Marcha por la Ciencia-CdMx" y del colectivo "Por Más Ciencia". Es motociclista, cinéfilo, bibliófilo, fotógrafo amateur y por supuesto, aficionado a los clubes de fútbol Pumas y Barcelona F.C.

\section{Mariana Esther Martínez-Sánchez}

Biomédica y estudió el Doctorado en Ciencias Biomédicas en la Universidad Nacional Autónoma de México. Es profesora de Asignatura de Matemáticas para la carrera de Biología en la Facultad de Ciencias en la UNAM. Se encuentra realizando un Posdoctorado en el Centro de Ciencias de la Complejidad. Colabora en el Taller/Portal Cienciorama desde 2015.

\section{Silvia Zenteno}

Licenciada en Ciencias Genómicas y Maestra en Ciencias Bioquímicas, por parte de la UNAM. Tomó un diplomado en Creación Literaria y otro en Literatura Infantil y Juvenil. Lleva cuatro años dedicándose a la escritura de artículos de divulgación científica y la elaboración de ilustraciones para el mismo fin. También le apasiona la creación de historias en forma de cuentos y novelas. Su meta en la vida es ser como Eleanor Abernathy cuando sea grande y en su otra vida reencarnar como un osito de agua. Colabora en el Taller/Portal Cienciorama desde 2014. 


\section{Cienciorama y la transmisión del conocimiento}

Adriana Pliego

"Implantes de memoria", ilustración realizada por Silvia Zenteno para el artículo Prótesis de la memoria escrito por Adriana Pliego
Aunque no podemos verlo ni tocarlo, el conocimiento es algo que puede pasar de una persona a otra como si fuera un objeto. Por ejemplo, cuando se propaga una noticia, quien participa o es testigo de un acontecimiento será el portador de un conocimiento en ese momento. Cuando cuenta a sus conocidos sobre lo sucedido, les entrega ese conocimiento, mismo que puede darse a otras personas de la misma manera que llegó a ellos. Las habilidades también se transmiten de persona a persona; por ejemplo, la de aprender a leer. Una vez que leemos y adquirimos cierta experiencia en ello, también podemos transmitir esa habilidad a otros. No es tangible, pero estamos seguros de que hubo un momento en que no conocíamos algo, y que una vez que se nos dio, es nuestro.

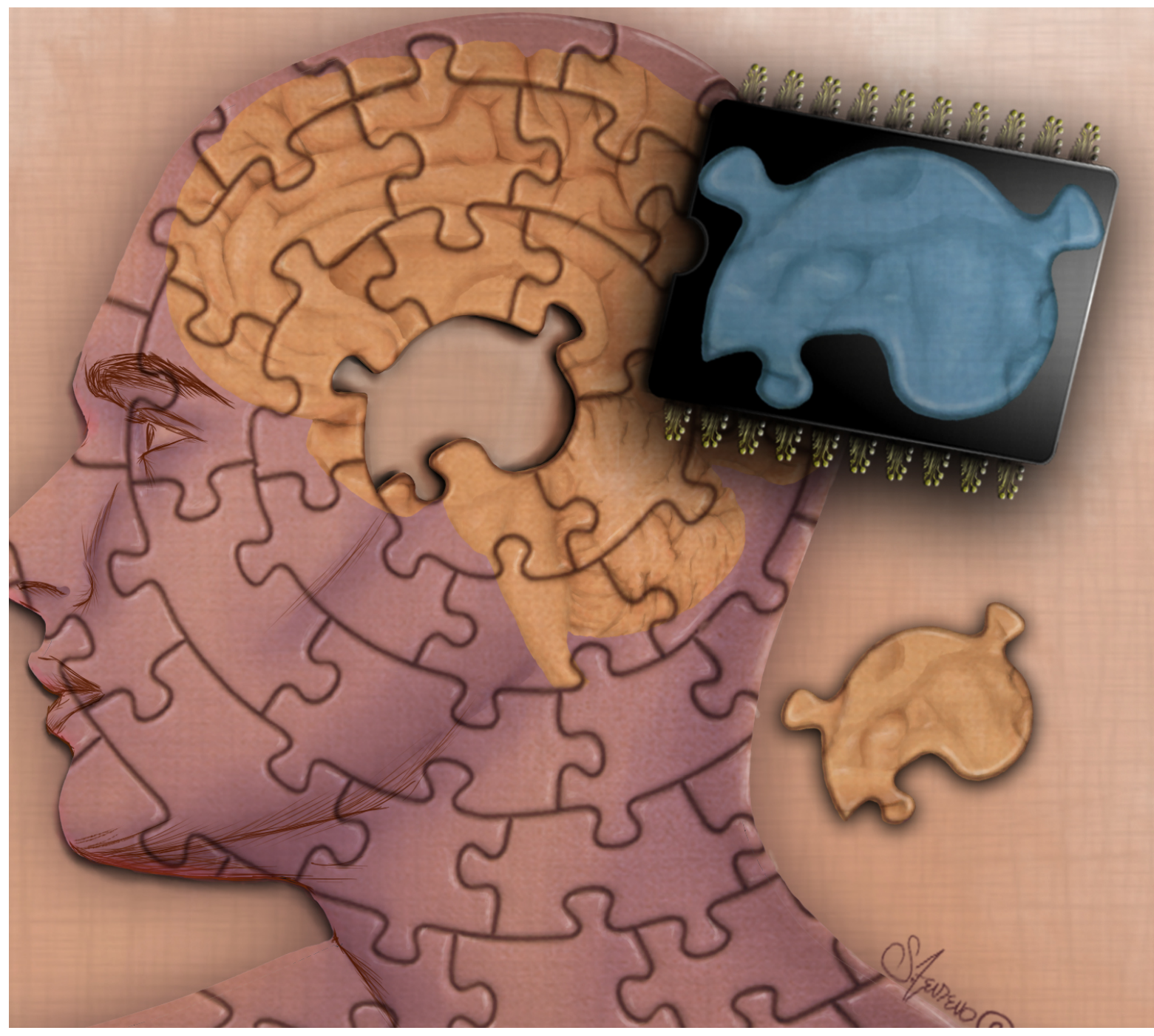


El conocimiento científico es como un regalo que se me ha otorgado desde muy joven a través de mis maestros, compañeros y otra variedad de personalidades en diferentes episodios de mi vida. Lo considero un conocimiento especial, no cualquiera. En un inicio se me dio sin que yo lo pidiera y, cuando lo tuve, me causó tal admiración y entusiasmo que me ha llevado a tomar decisiones personales importantes y actualmente está presente en gran parte de las actividades que realizo. Sin embargo, citando al personaje de televisión Sheldon Cooper durante las fiestas de Saturnalia, "el fundamento de dar regalos es la reciprocidad. No me has dado un regalo, Penny, sino una obligación".

En lo personal, la idea de la reciprocidad, además del gusto por la ciencia, es uno de los principales motivos por los que, desde que era estudiante de licenciatura, me he involucrado en actividades de divulgación científica. Pienso que una manera de retribuir el conocimiento científico recibido a lo largo de mi educación -en su mayoría en instituciones públicas- es compartiéndolo con la sociedad. Un medio para lograr este objetivo ha sido el taller de escritura creativa Cienciorama, el cual, además de permitirme escribir sobre cualquier tema de ciencia de mi interés, con un enfoque no formal, ameno, y mediante el uso de recursos literarios, me ha ayudado a definir un estilo aún en formación. Cienciorama es un espacio en donde los integrantes recibimos retroalimentación continua sobre nuestros trabajos, tanto de las editoras, como del resto de los talleristas que provienen de diferentes áreas como biología, matemáticas, química, física y filosofía. La diversidad de perspectivas no sólo enriquecen el contenido de los textos, sino también contribuyen a construirnos una postura frente a temas nuevos.

Como maestra de licenciatura he utilizado en clase textos de Cienciorama como apoyo para explicar, por ejemplo, temas como la radiación, el método científico o los biosensores, entre muchos más. En general, a los estudiantes les agradan los textos y gracias a ellos pueden explicar bien los conceptos de interés para la clase. Esto último es importante resaltarlo, pues en una sociedad con tanta información falsa disponible, en Cienciorama se tiene especial cuidado en 
la forma en que comunicamos los conceptos científicos, casi con el rigor de las revistas indizadas. Es mi deseo secreto que cuando mis estudiantes exploren el sitio web Cienciorama, en un click se enamoren de la ciencia y reciban el regalo que yo recibí y también contribuyan a repartirlo en nuestra sociedad, que tanto lo necesita.

\section{Ciencia y divulgación, un dúo inseparable}

\section{Carlos Alberto Velázquez Olivera}

Hasta antes de mi participación en Cienciorama había considerado a la divulgación de la ciencia como una actividad secundaria y que cualquier persona podía hacer. Pensaba que bastaba con entrevistar a alguien que supiera sobre ciencia para escribir un texto aceptable. Sin embargo, la experiencia resultó completamente inesperada. La primera vez que me platicaron sobre Cienciorama yo traía en la cabeza una idea sencilla que me parecía muy divertida, quizás para compartirla en una clase de física: explicar la segunda ley de la termodinámica a través de lo que le pasa a los bolillos. Puede parecer extraño, pero no se me ocurría una manera más directa de explicar a los demás que la segunda ley de la termodinámica es tan fundamental que todo el tiempo estamos lidiando con ella aunque no nos demos cuenta.

La experiencia resultó muy gratificante y estimulante, ya que bastó con escribir un borrador, darle forma y mandarlo al proceso de revisión interactiva de Cienciorama para que poco después saliera publicado en el portal. Esto me animó a escribir otras ideas que había tenido para comunicar algunas cosas que aprendí durante mis estudios de licenciatura, maestría y doctorado en física, o que resultaban de conversaciones o de las clases que he dado, pero que no tenía manera de canalizarlas y expresarlas siendo estudiante. La escritura se convirtió en un vehículo excelente para expresar todas esas ideas que yo quería transmitir pero que no encontraba un lugar donde plasmarlas.

Hoy en día, viendo un poco hacia atrás, puedo decir que Cienciorama me ha enseñado que la expresión escrita de nuestras ideas es un complemento necesario para todos los que estamos aprendiendo algo, pues nos da una manera muy personal de interactuar con el conocimiento que adquirimos, además de que me ha hecho comprender que la divulgación es una actividad necesaria de la ciencia. Dentro del ambiente de la divulgación se produce gran cantidad de ideas, analogías y metáforas, además de una cultura que gira alrededor de la ciencia, que aunque no incida de manera directa en la investigación, sí le da un sustrato enriquecido al animar a muchas personas a acercarse al conocimiento científico. Es como un abono que se le pone al árbol de la ciencia, que con el paso del tiempo nos dará sus frutos de nuevos descubrimientos. 


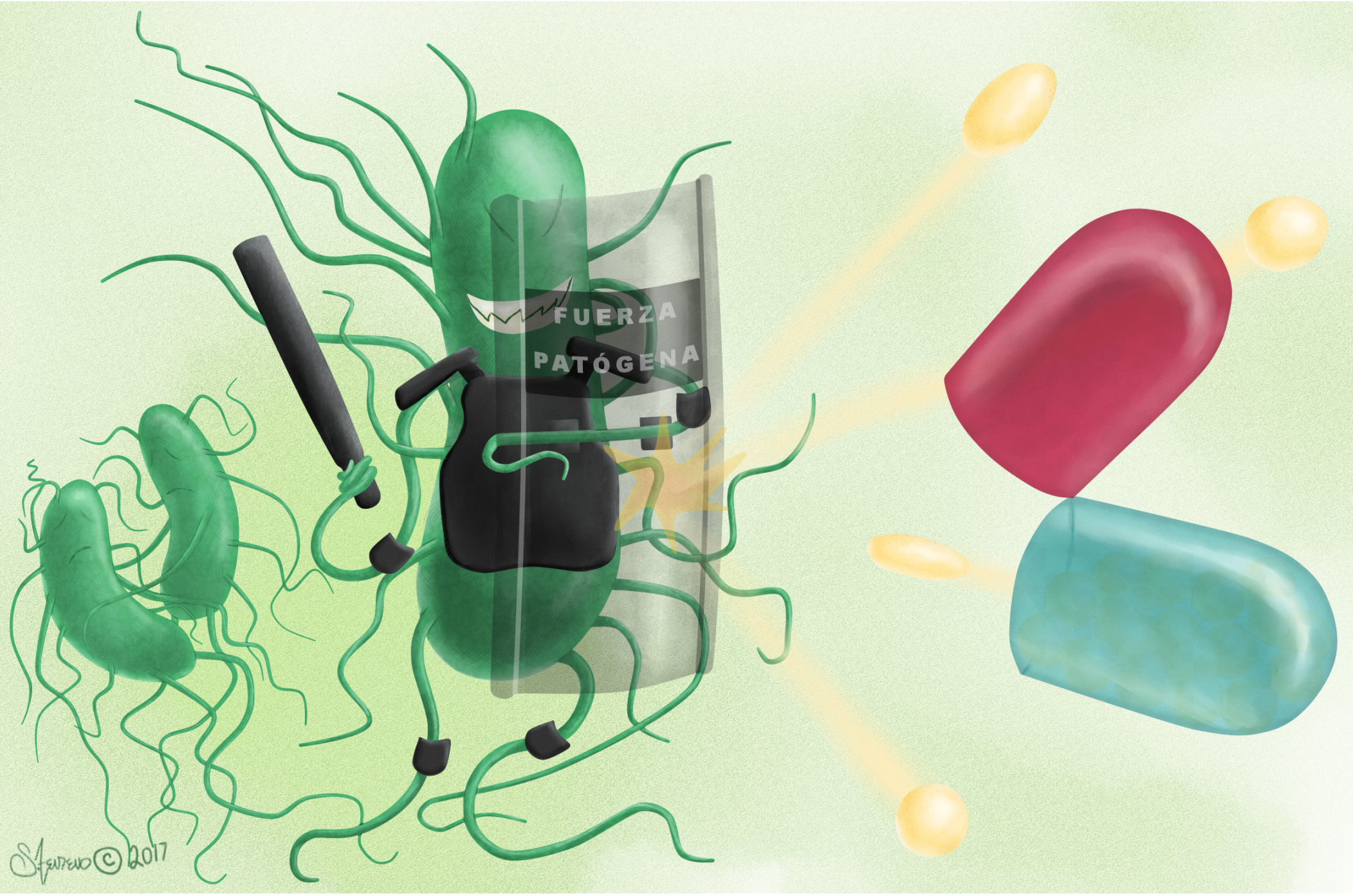

"Resistencia bacteriana", ilustración realizada por Silvia Zenteno para el artículo Resistencia bacteriana: ¿el fin de los antibióticos? escrito por Iván de Jesús Arellano Palma
Cienciorama y el ensayo de la libertad de expresión

Edgar Vargas Frías

"La lectura y el pensamiento crítico son peligrosos, ciertamente subversivos, en una sociedad injusta", dice Carl Sagan en su libro, El mundo y sus demonios. Este autor, uno de los divulgares más reconocidos que ha dado el mundo, es quizás una de mis más grandes influencias personales.

Por otro lado, me considero parte de la generación que en el año 2012 intentó impedir, por medio de las manifestaciones públicas callejeras, el retorno al poder de un partido político corrupto. Fue a mediados de mis veintes cuando 
empecé a entender y ejercer poco a poco mis derechos como ciudadano, así como a participar activamente en la política, tanto estudiantil, como nacional. Algo que en un país democrático sería trivial, pero que en el nuestro es algo que se ha vuelto muy peligroso. Basta conocer la cifras de activistas, periodistas y defensores de derechos humanos agredidos en los últimos años para darse una idea de lo peligroso que es criticar a los gobernantes.

El espacio que me dan en Cienciorama para escribir tiene toda la influencia de lo antes expuesto, por lo que trato de aprovecharlo para ayudar a difundir conocimiento científico y a la vez de exponer algunos problemas o acciones relacionadas con el quehacer científico. Nuestras editoras, al mismo tiempo que me han ayudado a mejorar los textos que presento, me han dado libertad de tocar esos temas de manera crítica, e incluso experimentar con formas narrativas para contar los hallazgos científicos que abordo.

"Cromatina", ilustración hecha por Silvia Zenteno para el artículo Reparar errores: cuestión de vida o muerte escrito por Iván de Jesús Arellano.

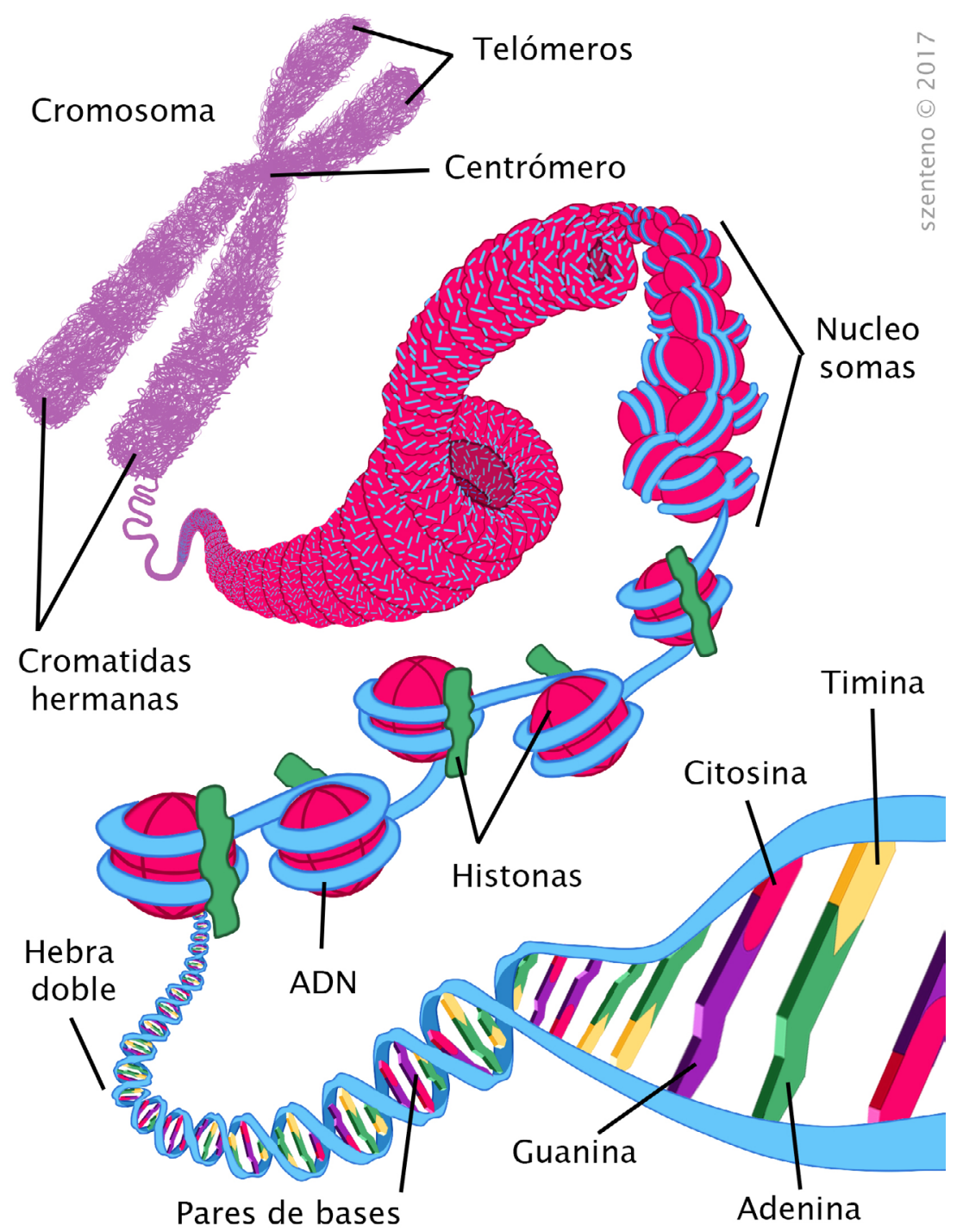

Pares de bases 
De esa forma he podido contar mi experiencia en movimientos sociales junto con los conocimientos adquiridos en mi posgrado en ciencias químicas. He sido capaz de escribir sobre química en general, estudios sobre del origen de la vida en la Tierra, la búsqueda de este fenómeno más allá de nuestro planeta; el hallazgo y estudio de exoplanetas; además de presentar textos críticos sobre la política científica, nacional e internacional y reportar actos como el encuentro que tuvieron científicos con pueblos indígenas de Chiapas o las protestas que estudiantes de posgrado -e investigadores- hemos realizado por los recortes económicos que ha sufrido el país en materia educativa y científica.

El proyecto Cienciorama se preocupa por publicar con rigor científico y literario, con libertad y con espíritu crítico, por lo que es un excelente espacio para colaborar. Contribuir a la ampliación de la cultura científica de todos es una gran responsabilidad, más, si uno se considera un estudiante comprometido con la sociedad, y es un auténtico placer hacerlo con toda la libertad creativa posible.

\section{Cienciorama y la interdisciplina}

Mariana Esther Martínez-Sánchez

La ciencia es un árbol que crece de una pequeña semilla para extender sus ramas al cielo y sus raíces a lo más profundo de la ciencia. Pero nuestro árbol no está solo. Conforme crece, sus ramas se entrecruzan con las ramas de otros árboles formando un bosque de conocimiento. Es en este enramado donde existen muchos de los complejos problemas que asolan a nuestra sociedad: la obesidad, la violencia, el cambio climático... y que no son el resultado de una sola causa, sino de la interacción de múltiples actores. Esto hace que para resolverlos se requiera también de la colaboración de múltiples expertos, desde el científico en su laboratorio hasta el campesino que conoce el problema de muy cerca. En estos problemas complejos, la experiencia de cada persona es valiosa para entender facetas diferentes del problema. A cada persona le ha tomado años de observación adquirir un conocimiento concreto y adquirir experiencia a través de la práctica. Sin embargo, esta misma diversidad de experiencias puede dificultar la comunicación. Si le preguntas a un físico, a un biólogo y a un sociólogo qué es el desarrollo de un sistema, los tres darán respuestas diferentes, determinadas por su área de estudio. He ahí una de las grandes dificultades de la interdisciplina: ¿cómo comunicarse con una persona que tiene una experiencia tan diferente?

Se trata de una pregunta absolutamente personal. Durante mi doctorado trabajé en el desarrollo de modelos matemáticos para entender el sistema 


\section{Cienciorama y el encuentro con el arte}

Silvia Zenteno

"Cerebro y fuego", ilustración realizada por Silvia Zenteno para el artículo

\section{Dime con quién andas y te} diré quién eres escrito por Silvia Zenteno De León.

Todo comenzó en la primaria. La tarea, hacer el dibujo de un rinoceronte. Pero por más que lo borraba y lo volvía a trazar, no me gustaba. Quería que se viera igualito al de la foto, lo quería perfecto. Pero nada que quedaba. Mi mamá ofreció ayudarme a arreglarlo, pero yo quería que me saliera a mí. No recuerdo qué tan satisfecha quedé con el resultado en aquel momento, pero fue el inicio de mi gusto por la ilustración.

Desde entonces, pasé por varios cursos de dibujo, y el lápiz y la acuarela se convirtieron en mis técnicas favoritas. Sin embargo, a la hora de elegir carrera, mi lado racional matemático-biológico se impuso sobre mi lado artístico al que también le gustaba escribir historias. Grave error. O alguna vez lo llamé así. Porque sin importar cuánto me guste la ciencia y que me emocione cada que leo un artículo científico o de divulgación, no es suficiente para mí, necesitaba expresar mi lado artístico, y, seamos francos, la ciencia es una profesión celosa que exige toda tu atención y tiempo. Pero si sólo me dedicaba a dibujar y a escribir, ¿sería suficiente para mí? No, la ciencia también forma parte de mí. Ha forjado la manera en la que veo el mundo y cómo me enfrento a los problemas. No podía simplemente ignorar mi fascinación por todo lo relacionado con el cerebro. Entonces, ¿cómo combinar ambas partes esenciales para mí? La respuesta fue la divulgación de la ciencia. Pero ¿por dónde empezar?

Cienciorama es un proyecto que permite que estudiantes sin experiencia se acerquen a la divulgación de la ciencia a través de un taller formativo y un portal electrónico que nos da un espacio para compartir nuestros escritos, ayudándonos a mejorar nuestras habilidades de comunicación con el público en general por medio de críticas constructivas y la práctica. Originalmente me uní con la idea de poder aplicar en mis artículos las herramientas literarias que adquirí en el Diplomado en Creación que cursé, pero en la primera reunión a la que asistí me enteré que buscaban entre los colaboradores un ilustrador para las figuras de los artículos. No muy segura de que lo que hasta entonces hacía por mera diversión fuera suficiente, levanté 


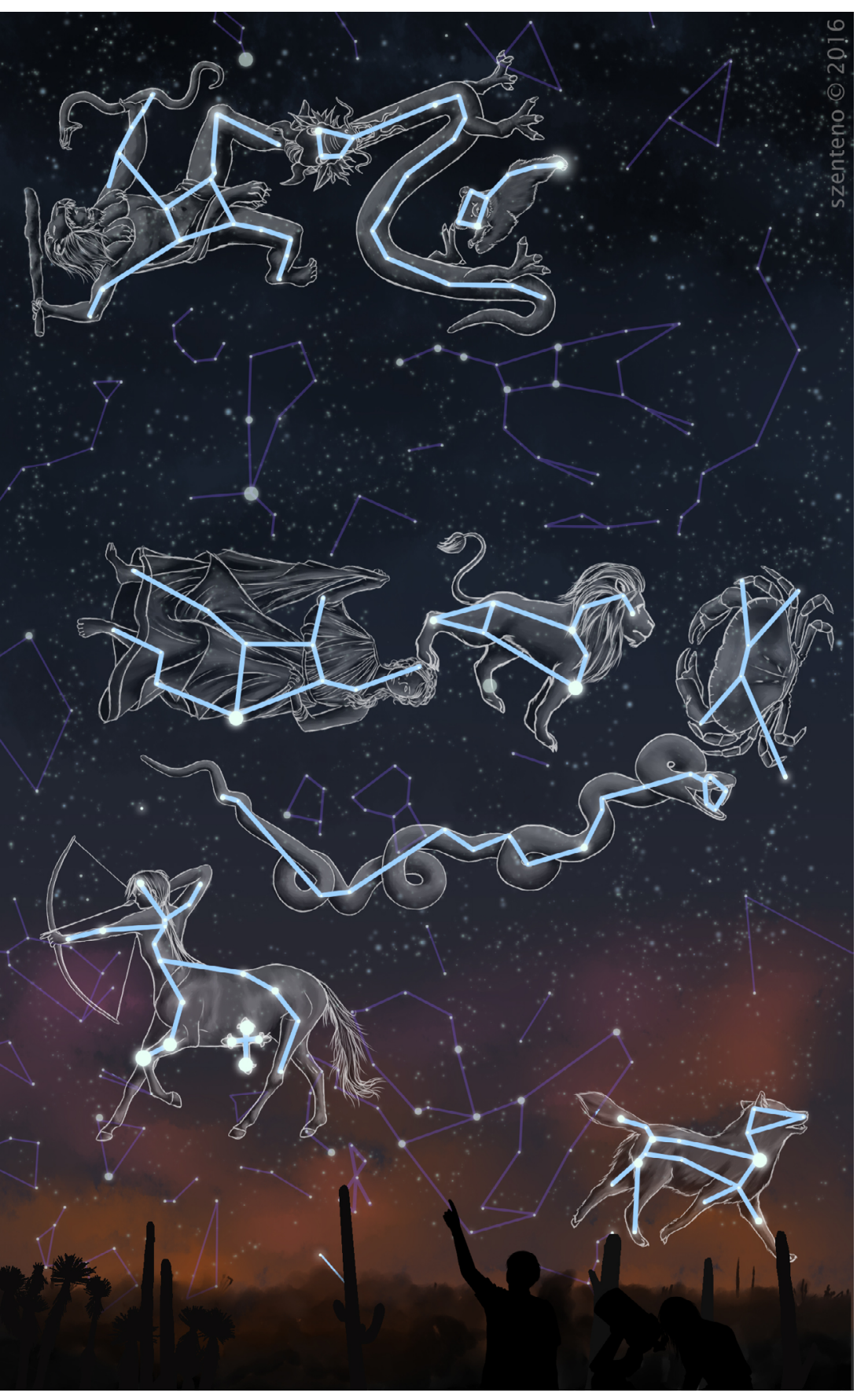

la mano. El inicio fue arduo. En aquel entonces tenía poca experiencia con ilustración digital y las coordinadoras querían un estilo que distinguiera a Cienciorama. Pero poco a poco logramos acoplarnos; yo aprendí la forma en la que ellas querían que se expresaran las imágenes y ellas me fueron dando cada vez más "libertad artística".

Cienciorama me ha dado la oportunidad de desarrollarme como divulgadora, fusionando mi entusiasmo por la ciencia y mi pasión por escribir e ilustrar. Ha sido la incubadora que me ha permitido incursionar en el complejo mundo de la divulgación de forma amigable, otorgándome los instrumentos necesarios para compartir mi entusiasmo con el público, así como oportunidades que en ningún otro lugar podría haber encontrado.

Cada que me siento a escribir un artículo nuevo, recuerdo mucho la vez que reprobé, junto con el resto de mis compañeros, un examen durante el primer semestre de la licenciatura. Nuestro profesor, un renombrado investigador al que por lo demás le tengo alta estima, nos dijo enfurecido que así nunca seríamos verdaderos científicos, sólo unos simples reporteros de la ciencia. Es el concepto en el que muchos investigadores tienen a la divulgación, cuando, en vez de usarla como insulto, debieran ser los primeros interesados en dar a conocer sus avances, y es un estigma que tenemos que romper, porque, parafraseando al Dr. Félix Recillas, otro de mis profesores de la licenciatura y la maestría: "Uno no puede llamarse científico si no es capaz de hacer que hasta su abuelita entienda la relevancia de la ciencia con la que trabaja". A mi parecer, Cienciorama cumple una función trans-

"El paseo de las constelaciones", ilustración realizada por Silvia Zenteno para el artículo "A la luz de las estrellas, manual para astrónomos y enamorados" escrito por Carlos Alberto Velázquez Olivera. cendental en la formación de divulgadores, enseñándonos a transmitir y compartir tanto el conocimiento como el fervor que sentimos por la ciencia. Pero no sólo tiene las puertas abiertas para todos aquellos a los que les interesa la divulgación, además, resulta una plataforma única en la labor de atraer hacia la divulgación a científicos en formación, que quizá sólo desconocían su encanto por falta de oportunidades, motivaciones o apoyo para realizarla. 


\section{Cómo citar este artículo}

* Martínez-Sánchez, M. E., Pliego, A., Vargas Frías, E., Velázquez Olivera, C. A. y Zenteno, S. (2018). (Proto)escritores de ciencia en Cienciorama. Revista Digital Universitaria (RDU). Vol. 19, núm. 2 marzo-abril. DOI: http://doi.org/10.22201/ codeic.16076079e.2018.v19n2.a7. 